\title{
A PROSPECTIVE STUDY OF CRANIAL ORTHOTIC TREATMENT OF INFANTS WITH ISOLATED DEFORMATIONAL BRACHYCEPHALY
}

Kevin M. Kelly ${ }^{1}$, Edward Joganic ${ }^{2}$, Stephen P. Beals ${ }^{3}$, Jeff A. Riggs ${ }^{4}$, Mary Kay McGuire ${ }^{4}$, Timothy R. Littlefield $*^{4}$

${ }^{1}$ University of Iowa, Iowa City, IA, USA.

${ }^{2}$ Barrow Cleft and Craniofacial Center, Phoenix, AZ, USA.

${ }^{3}$ Southwest Craniofacial Center, Phoenix, AZ, USA.

${ }^{4}$ Cranial Technologies, Tempe, AZ, USA.

*Email:tlittlefield@cranialtech.com

DOI: https://doi.org/10.33137/cpoj.v1i2.32024

\section{OBJECTIVES}

The study objectives were to prospectively evaluate treatment results of infants presenting with isolated deformational brachycephaly following use of a cranial orthosis, and to investigate the role of entrance age on efficacy of treatment.

\section{METHODS}

128,014 infants presenting for consultation to one of thirty clinics were included from January 2013 through December 2017. Nonsynostotic, nonsyndromic infants presenting with isolated deformational brachycephaly, characterized as a Cephalic Index $\geq 90$, and craniofacial asymmetry $\leq 3 \mathrm{~mm}$, were identified and filtered from the database. An Analysis of Variance (ANOVA) was performed, examining the change in cephalic index with respect to three independent variables (entrance age, treatment time, initial cephalic index).

\section{RESULTS}

4,205 infants were identified. Mean entrance age was 5.8 months, and mean treatment time was 13.5 weeks. There was a statistically significant $(\mathrm{p}<0.001)$ improvement in cephalic index from 95.0 to 89.4 (an $81.4 \%$ improvement towards normal). The ANOVA analysis demonstrated an inverse relationship between entrance age, and both treatment outcome and treatment time. Cephalic index improved by $5.8 \%, 5.4 \%$, and $4.3 \%$ in the $\geq 3$ to $<6, \geq 6$ to $<9$, and $\geq 9$ to $12 \leq$ month groups respectively. Likewise, there was a statistically significant relationship between entrance age and treatment time $(p<0.001)$. Treatment time was 11.9, 15.8, and 17.4 weeks respectively.

\section{CONCLUSION}

As discussed, deformation of the cranium in infancy represents a spectrum of deformity, ranging from severe asymmetric yet proportional distortion of the skull in plagiocephaly, to nearly symmetric yet disproportional distortion in brachycephaly. As such, the condition is best described as deformational plagiocephalybrachycephaly (DPB) with isolated plagiocephaly and/or isolated brachycephaly being at either ends of the spectrum. These findings demonstrate that the cranial orthosis is successful in the treatment of deformational brachycephaly, and that entrance age influences treatment results, with younger infants demonstrating both improved outcomes and shorter treatment times.

\section{KEY WORDS}

Deformational Brachycephaly, Cranial Orthosis, Flat Head Syndrome, Cephalic Index

\section{ADDRESS CORRESPONDENCE}

Timothy R. Littlefield, Cranial Technologies, Inc., 1395 W. Auto Drive, Tempe AZ, 85248 [tlittlefield@ cranialtech.com], Phone: 480-4036332, Fax: 480-505-1842 